\title{
Endocrown - The Realm of Post-Free Endodontic Restorations
}

\author{
Anupreeta Anwarullah¹, Ravi Kumar Konagala², Murali Krishna Raju³, Amara Swapna Lingam4, Lakshman Varma U \\ 1,2, 5 Department of Conservative Dentistry and Endodontics, GITAM Dental College and Hospital \\ Visakhapatnam, Andhra Pradesh, India. ${ }^{3}$ Department of Conservative Dentistry and Endodontics, GSL \\ Dental College and Hospital, Rajahmundry, Andhra Pradesh, India. ${ }^{4}$ Department of Surgical and \\ Diagnostic Science, Dar A Uloom University, Riyadh, Saudi Arabia.
}

\section{INTRODUCTION}

With increased dental awareness, there has been a growing trend in patients who are opting for teeth retention, so post-endodontic restorations play a significant role in dictating restoration longevity. However, till date restoration of root canal treated teeth is still controversial. Root canal treated teeth often suffer from extensive loss of tooth structure because of access cavity preparation, caries removal, replacement of restoration and trauma. ${ }^{1}$

Traditionally the restorative material of choice for an endodontically treated molar would be post and core followed by metal / ceramic crowns. However, studies have shown that these intra-canal posts may increase risk, of undermining the residual tooth structure, root perforation and catastrophic failures. ${ }^{2}$

With adhesive strategies, there has been a paradigm shift towards post-less restorations and utilisation of pulp chamber as an extension, thus integrating the crown and core as a single unit or monobloc. ${ }^{2,3}$ This was the concept of the endocrown technique. ${ }^{3}$ Bindle and Mormann first, delineated the use of porcelain adhesive endodontic crowns. ${ }^{4}$ Endocrowns are more practical, conservative, aesthetic, simple to fabricate, economical, less time consuming and allows favourable distribution of masticatory stresses. Most studies on endocrowns showed comparable or somewhat superior results to other conventional treatments for endodontically treated teeth (ETT). However, the available literature is based largely on the use of ceramic endocrowns. ${ }^{2-4}$

It was observed that data pertaining to endocrown fabrication with other indirect restorative materials is still limited, and the choice is still unclear. Indirect composites show enhanced mechanical properties, creation of ideal contacts and contours, favourable wear, aesthetics and can serve as an economical alternative to ceramics. ${ }^{5}$ Hence, this paper attempts to present a case report of functional and aesthetic rehabilitation of an endodontically treated molar with an endocrown restoration utilising indirect composite (SR Adoro System).

\section{PRESENTATION OF CASE}

A 40-year-old male patient reported to the Department of Conservative Dentistry and Endodontics, with the chief complaint of dislodged restoration in the left lower back tooth region (Figure 1a). Patient was asymptomatic with no pain in relation to associated tooth. Medical history was non-contributory. Patient gave history of endodontic treatment in a private clinic with the associated tooth few months back. However, due to time constraints he could not follow through with permanent restoration. Clinical examination revealed a dislodged restoration in relation to 36 with mesial portion of wall missing. The distal wall, major portion of buccal and lingual wall were intact with surrounding healthy gingiva. Radiographic examination showed satisfactory endodontic treatment with no periapical changes seen.
Corresponding Author: Dr. Anupreeta Anwarullah, Maharanipeta,

Visakhapatnam-530002,

Andhra Pradesh, India.

E-mail: dr.anupreeta@gmail.com

DOI: $10.14260 / j e m d s / 2021 / 254$

How to Cite This Article:

Anwarullah A, Konagala R, Raju MK, et al. Endocrown - The realm of post-free endodontic restorations. J Evolution Med Dent Sci 2021;10(16):1187-1190, DOI: 10.14260/jemds/2021/254

Submission 07-12-2020,

Peer Review 17-02-2020,

Acceptance 25-02-2020,

Published 19-04-2021.

Copyright (C) 2021 Anupreeta Anwarullah et al. This is an open access article distributed under Creative Commons Attribution License [Attribution 4.0 International (CC BY 4.0)] 


\section{CLINICAL DIAGNOSIS}

The diagnosis was an endodontically treated tooth with respect to 36 with dislodged access cavity restoration.

\section{DISCUSSION OF MANAGEMENT}

Post endodontic restorative treatment was planned based on residual tooth structure and patient criteria. The patient requirement was an aesthetic and a more economically feasible permanent restorative option. Conventionally the treatment plan for an endodontically treated tooth would be a prosthetic crown with post and core depending on tooth structure loss. However, taking into consideration the remaining sound tooth structure available, and the goal being reinforcement and conservation of residual tooth integrity, an adhesive endocrown restoration was planned to meet the patient's requirements. Patient was explained the varied treatment options and final treatment plan. Informed consent was taken from patient prior to treatment.

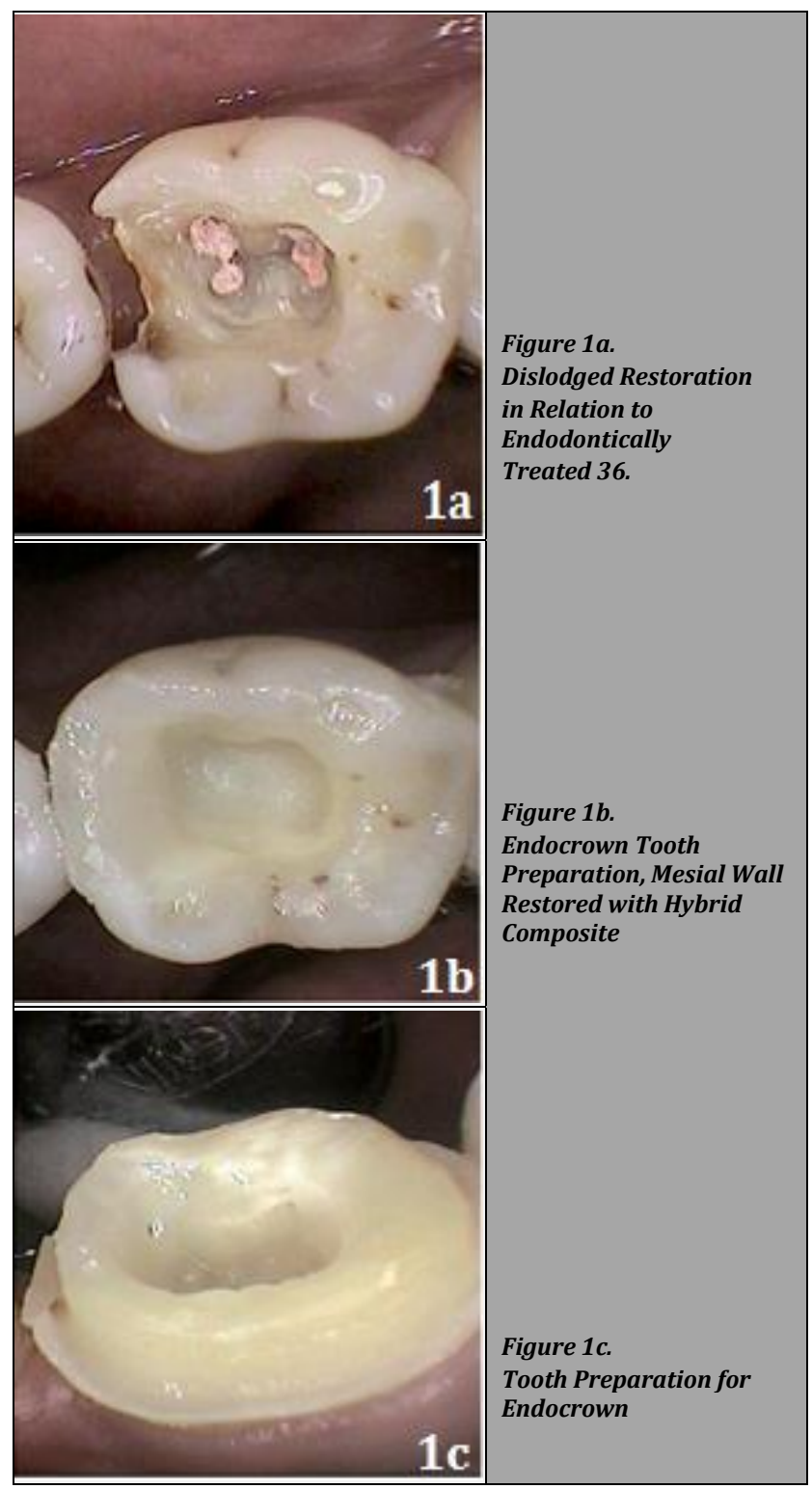

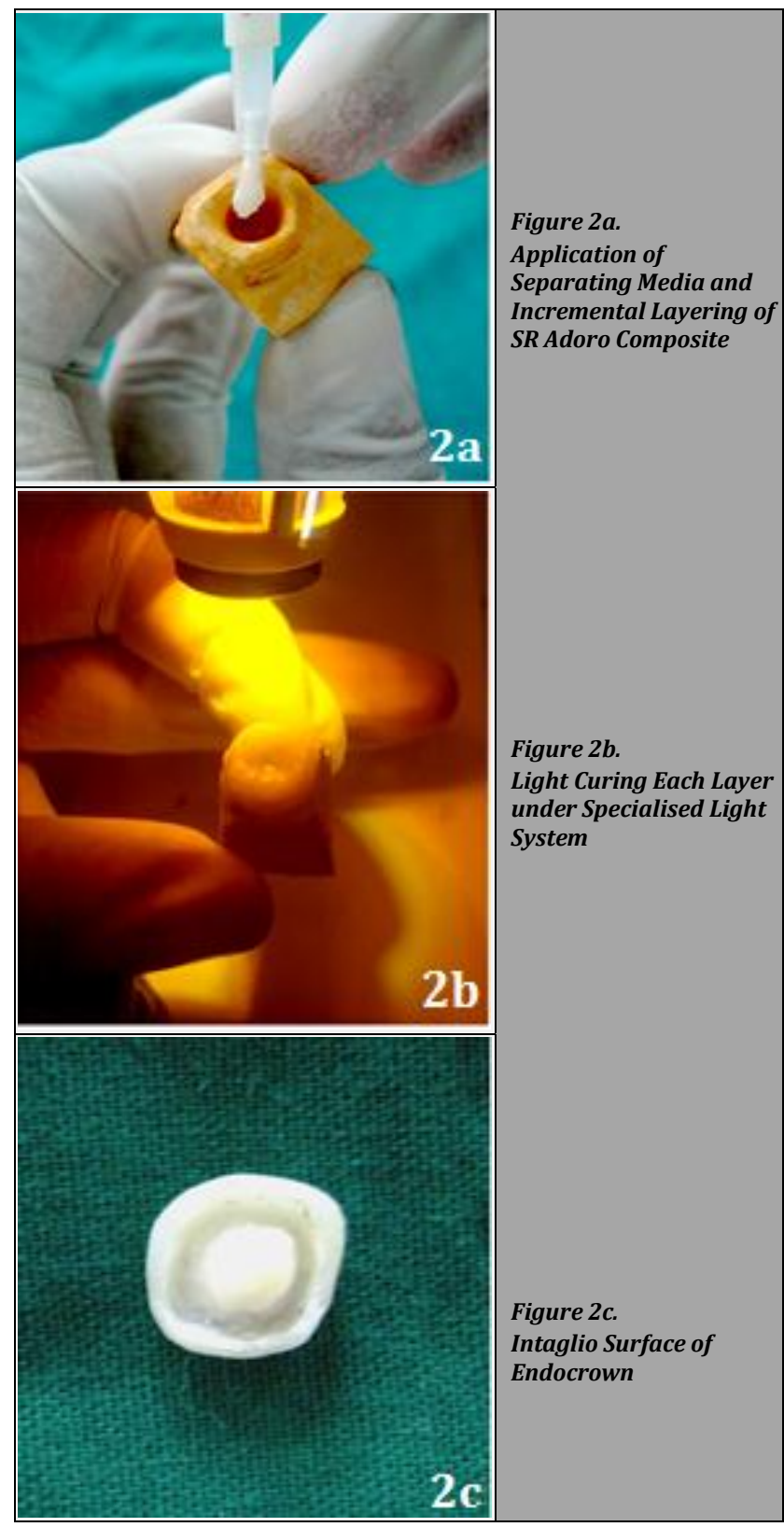

Excess gutta-percha was removed near orifice and lined with glass ionomer cement (3M ESPE Vitrebond). The missing mesial wall was restored with a microhybrid composite (Tetric Ceram, Ivoclar Vivadent). Gutta percha was removed up to $2 \mathrm{~mm}$ in the orifices to take advantage of the saddle like anatomy of the cavity floor. Access cavity was relined with flowable composite (Tetric Flow, Ivoclar Vivadent, Liechtenstein, Germany) to eliminate undercuts (Figure 1b). The endocrown preparation was adapted from the technique recommended by Michel Fages. ${ }^{6}$

Endocrown preparation was done using a cylindrical diamond bur with $7^{0}$ occlusal convergence creating an overall $1.5 \mathrm{~mm}$ reduction and a butt joint supragingival finish line forming a "cervical sidewalk". Variation in margin levels was linked by a slope of $\leq 60^{\circ}$ preventing a staircase effect (Figure 1c).

After margins refinement, an elastomeric impression with (Polyvinyl siloxane silicone (HydroXtreme, Coltene / Whaledent, Cuyahoga Falls, OH, USA) was made, die was fabricated, and an endocrown restoration was fabricated incrementally using indirect composite SR Adoro system 
(Ivoclar Vivadent, Germany) as per manufacturer instructions (Figure 2).
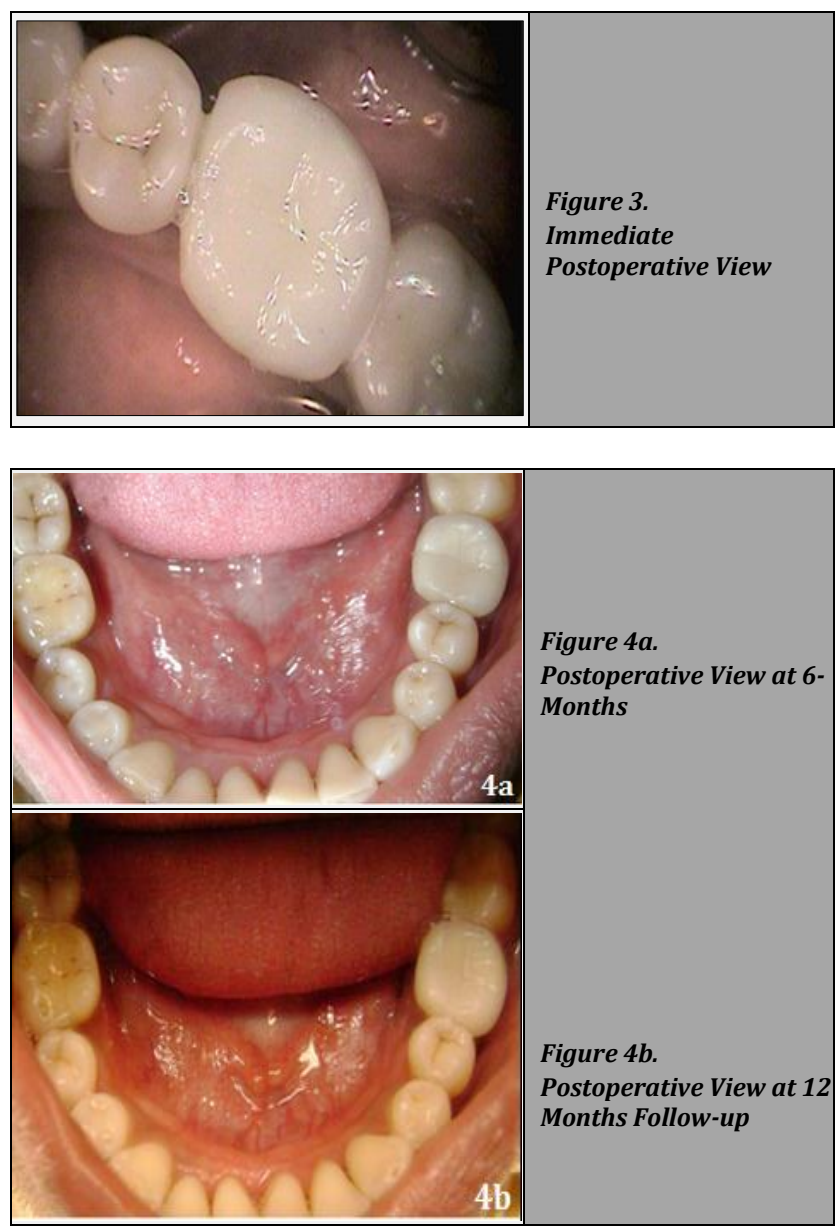

In the interim period, a provisional restoration was fabricated with self-cure acrylic (DPI-RR Cold Cure, India) on cast and cemented with temporary cement (Nogenol temporary cement, GC America Inc). At the try-in appointment, the fabricated restoration was tried intraorally to check for marginal discrepancy, occlusal high points, proximal contour and after minor modifications, finishing and polishing was done. The intaglio surface of restoration was treated with hydrofluoric acid (IPS ceramic etching gel, Ivoclar Vivadent, Schaan, Liechtenstein) and cavity surface was etched with 37 $\%$ phosphoric acid (Ivoclar Vivadent, Schaan, Liechtenstein) for 10 s, rinsed for 30 s and adhesive resin (Tetric $\mathrm{N}$ Bond, Ivoclar Vivadent, Schaan, Liechtenstein) was applied for $10 \mathrm{~s}$ and light cured (QTH 3M - ESPETM XL 2500, $850 \mathrm{Mw} / \mathrm{cm}$, USA) for 20s. Dual cure resin (Variolink N, Ivoclar Vivadent, Amherst, USA) was used for cementation and cured from all sides (Figure 3). Follow up evaluation was done at 6 and 12 months. The restoration was functional and intact (Figure 4).

\section{DISCUSSION}

Contrary to previous belief, it has been reported that stiffness and decrease in moisture do not play a significant role, rather the loss of tooth structure following access preparation deteriorates tooth integrity in ETT compared to vital teeth.7,8 The conventional restorations including posts and crowns further predispose ETT to catastrophic failure.
From a biomimetic view, tooth conservation sustains a balance between mechanical, biological, adhesive, functional, and aesthetic factors. ${ }^{1}$ Hence, there is a quest for post endodontic restorations that conserve and reinforce the residual structure. With advances in adhesion and following the principles of minimally invasive dentistry (MID), one approach could be the utilisation of endocrowns for ETT. 9

The endocrown preparation consists of an equigingival butt joint finish margin and central retention cavity into pulp chamber. The rationale is that macro-mechanical retention is obtained by the pulpal chamber and cavity margins, and micro-retention by adhesive cementation. $2,9,10$

The endocrown technique offers various unique advantages which include, the relatively simple preparation, root canals are not engaged, and is less traumatic. They are more practical, conservative, aesthetic, simple to fabricate, economical, less time consuming and allows favourable distribution of masticatory stresses. 9,10

The supragingival cervical margin positioning protects marginal gingiva, facilitating impression procedures, and conserves the remaining tooth. Forces are distributed to the cervical butt joint (compression) and axial walls (shear force), moderating the pulpal floor load. Thus, the endocrown is a very feasible treatment alternative for mechanical and aesthetic rehabilitation of ETT molars and is compatible with goals of minimal invasive dentistry. 9,11

In 2012, Biacchi et al. compared the force distribution of traditional fiber post-core-crown and endocrown and found more favourable results with endocrowns. ${ }^{12}$ Based on systematic review and meta-analysis by Sedrez-Porto et al. endocrown restorations performed better in comparison to conventional restorations in terms of fracture strength. ${ }^{2}$ This is in accordance with other studies which have proven the validity of bonded endocrowns in comparison to traditional crowns. ${ }^{8,3,10,13}$

Coming to material choice, feldspathic ceramic, glass ceramic, hybrid composites, and newest CAD / CAM (computer-aided design / computer-aided manufacturing) resin blocks can be used for endocrown fabrication. However, with ceramics, there is a risk of debonding and root fracture because of difference in the modulus of elasticity of ceramics and dentine. ${ }^{14}$

An alternative approach could be utilisation of indirect composites which show enhanced mechanical properties, creation of ideal contacts and contours, favourable wear, and esthetics. ${ }^{5}$

In the present case indirect composites [SR ADORO] was used as they ensure a better marginal fit, are less abrasive, more economical and possess elastic modulus and stress behaviour similar to dentin allowing favourable stress distribution compared to ceramics.5,15 Although CAD / CAM technique offers good precision, it entails an expensive procedure and additional time in terms of laboratory processing and equipment. Hence, the above procedure of SR ADORO fabrication was followed, keeping in mind patients' economic constraints, as it is cost effective and time saving.

The SR Adoro system is a second-generation indirect composite comprising of homogeneous micro filled composite and $64-65 \mathrm{wt} \%$ of inorganic fillers.

The improved properties of SR Adoro can be attributed to the high quotient of nanoscale inorganic fillers and urethane dimethacrylate (UDMA), matrix which is characterised by its 
superior toughness compared to BISGMA. ${ }^{16}$ Indirect composites could be the intermediate restorative option bridging ceramic and direct composites.5,15,16 With proper case selection, endocrowns fabricated with indirect composites could be a promising option for ETT. However, these remain mostly underutilised.

\section{CONCLUSIONS}

There is no elixir, and there is a place for all restorative materials used in dentistry. With precise attention to detail, utilised appropriately, indirect composite restorations may prove to be a viable, economical and conservative alternative for post endodontic restorations in certain specific clinical scenarios. Endocrowns fulfil the concept of biomechanical integration in posterior ETT. Nevertheless, longer follow-up periods and clinical studies are warranted to ascertain the longevity and physical properties of endocrowns fabricated with indirect composites.

Financial or other competing interests: None.

Disclosure forms provided by the authors are available with the full text of this article at jemds.com.

\section{REFERENCES}

[1] De Carvalho MA, Lazari PC, Gresnigt M, et al. Current options concerning the endodontically - treated teeth restoration with the adhesive approach. Braz Oral Res 2018;32(Suppl 1):e74.

[2] Sedrez-Porto JA, Rosa WL, Da Silva AF, et al. Endocrown restorations: a systematic review and meta-analysis. J Dent 2016;52:8-14.

[3] Hamdy A. Effect of full coverage, endocrowns, onlays, inlays restorations on fracture resistance of endodontically treated molars. Journal of Dental and Oral Health 2015;1(5):1-5.
[4] Bindle A, Mormann WH. Clinical evaluation of adhesively placed cerec endo-crowns after 2 years--preliminary results. J Adhes Dent 1999;1(3):255-65.

[5] Nandini S. Indirect resin composites. J Conserv Dent 2010;13(4):184-94.

[6] Fages M, Bennasar B. The endocrown: a different type of all-ceramic reconstruction for molars. J Can Dent Assoc 2013;79:d140.

[7] Dietschi D, Duc 0, Krejci I, et al. Biomechanical considerations for the restoration of endodontically treated teeth: a systematic review of the literature, Part II (Evaluation of fatigue behavior, interfaces and in vivo studies). Quintessence Int 2008;39(2):117-29.

[8] Al-Dabbagh RA. Survival and success of endocrowns: a systematic review and meta-analysis. J Prosthet Dent 2020;S0022-3913(20)30079-2.

[9] Sevimli G, Cengiz S, Oruc MS. Endocrowns: review. J Istanb Univ Fac Dent 2015;49(2):57-63.

[10] Waad A. Endocrowns: a review article. Sch J Dent Sci 2018;5(5):306-9.

[11] Dogui H, Abdelmalek F, Amor A, et al. Endocrown: an alternative approach for restoring endodontically treated molars with large coronal destruction. Case Rep Dent 2018;2018:1581952.

[12] Biacchi GR, Mello B, Basting RT. The endocrown: an alternative approach for restoring extensively damaged molars. J Esthet Restor Dent 2013;25(6):383-90.

[13] Botto EB, Baron R, Botto JLB. Endocrowns: a retrospective patient series study, in an 8-to-19-year period. Odontoestomatología 2016;18(28):45-56.

[14] Veselinovic V, Todorovic A, Lisjak D, et al. Restoring endodontically treated teeth with all ceramic endocrowns case report. Serbian Dental J 2008;55:54-64.

[15] Ramirez-Sebastia A, Bortolotto T, Roig M, et al. Composite vs ceramic computer-aided design/computer-assisted manufacturing crowns in endodontically treated teeth: analysis of marginal adaptation. Oper Dent 2013; 38(6):663-73.

[16] Adoro SR. Instruction manual. adoro_clinical_ guide_e1.pdf (ttlschouten.nl) Accessed on 2020 Dec 14. 